\title{
Research on the Dilemma of Taxi Management in China from the Perspective of Game Theory
}

\author{
Haowen Feng* \\ Shanghai University of Political Science and Law \\ Shanghai, China, 201701 \\ fenghaowen@shupl.edu.cn
}

\author{
Weimin Ouyang \\ Shanghai University of Political Science and Law \\ Shanghai, China, 201701 \\ oywm@shupl.edu.cn
}

\begin{abstract}
On the one hand, technical threshold of the taxi business in China is low, a lot of people can do a taxi driver, on the other hand, taxi business carries out a system of access permission, has a very high monopoly profits. Only have to pay a lot of cost, the driver can become legal taxi driver in the system; otherwise, if engaged in the taxi business, he is illegal, called as "black car". In order to maintain the vested monopoly interests of taxi business, the law enforcement agency takes the "fishing enforcement" to effectively fight against "black car", which caused a lot of trouble, damaged the government image, and destroyed the social harmony. The management of taxi market is in a great trouble. In this paper, we use game theory to analyze the dilemma of taxi management in China, reveal the inherent reasons of "fishing enforcement", and put forward the corresponding suggestions.
\end{abstract}

Keywords-Game Theory, Nash Equilibrium, Taxi Management, Fishing Enforcement

\section{INTRODUCTION}

On the taxi management system under the current, China's taxi management mainly has two kings of management modes such as "Beijing model" and the "Shanghai model". The socalled "Beijing model" refers to the separation of property rights and the mode of operation, that is, the contracting business model [3, 4].

The taxi company obtains the right to operate a taxi business from the government departments, driver is to buy car, bears operating costs, and pays management fees to the taxi company by month. The so-called "Shanghai model" refers to the unification of the property right and the management right and is operated by the company, namely "government operation of taxi" mode. The main approach of this model is that the taxi company obtains the right to operate a taxi business from the government departments, buy cars, vehicles, and hires drivers. The relationship between company and the drivers is a pure employment relationship. The income of taxi driver is basic salary plus sales commissions.

No matter what kind of management mode, the taxi market has a high entry threshold. If the driver wants to be engaged in the taxi business legally, he must obtain the operation qualification, must pay quite high entry cost. In the urban taxi business, the local government and taxi companies enjoy most of the benefits, while the taxi drivers enjoy a very small part of the benefits.

If the driver is engaged in the taxi business without a legally operating qualification, he is the illegal operation, commonly known as "black car". The "black car" has a high risk to be investigated and punished by the law enforcement. However, it is very difficult to investigate and punish the "black car", the main problem is difficult to obtain evidence, because the "black car" and "private car" have the same appearance, the only difference is that the "black car" in the process of moving will appear transaction behavior such as bargaining and payment, and the transaction behavior is hidden, it is almost impossible for the law enforcer to find transaction behavior on the spot.

In order to facilitate to obtain evidence of "black car" which is engaged in the illegal taxi business, law enforcement agency will often take the strategy of "fishing enforcement", that is to recruit persons to help investigate though the establishment of prizes reporting system, these assistants manage to obtain evidence for "black car" to be engaged in the illegal taxi business by way of posing as passengers, hen give the evidence to law enforcement agency to punish "black car". On the one hand, the "fishing enforcement" greatly improves the efficiency of the investigation "black car", and effectively protects the taxi market monopoly profits; on the other hand, driven by the interests, the "fishing enforcement" wronged many kindhearted owners of "private cars".

In this paper, we use game theory to analyze the dilemma of taxi management in China $[1,2,5,6]$, reveal the inherent reasons of "fishing enforcement", and put forward the corresponding suggestions.

\section{The GAME BETWEen TrafFIC WARDEN AND DRIVER}

Assume that the strategy choices for traffic warden are "investigate" and "not investigate", the benefit and cost for traffic warden to investigate "black car" are $\mathrm{X}$ and $\mathrm{C}$ respectively. And also that the strategy choices for drive are "legal" and "illegal", the benefit for drive to operate taxi business is $\mathrm{Y}$, the cost for drive to legally operate taxi business is $\mathrm{M}$, and the cost for drive to illegally operate taxi business is $\mathrm{N}$. Based on the above description, the game's payoff matrix is shown in table 1. 
TABLE I. THE GAME'S PAYOFF MATRIX BETWEEN TRAFFIC WARDEN AND TEAM DRIVER

\begin{tabular}{|c|c|c|c|}
\hline & \multicolumn{3}{|l|}{ driver } \\
\hline \multirow{3}{*}{ traffic warden } & & legal & illegal \\
\hline & investigate & -C, Y-M & $\mathrm{X}-\mathrm{C}, \mathrm{Y}-\mathrm{N}$ \\
\hline & Not investigate & 0, Y-M & $0, \mathrm{Y}$ \\
\hline
\end{tabular}

Traffic services personnel and the driver are assumed to be the rational economic man, namely each participant action guidelines for personal benefit maximization. Assume that the traffic warden and driver are rational economic man, whose action criterion is to maximize the interests of the individual.

According to the relationship between the illegal operating cost $\mathrm{M}$ and the legal operating cost $\mathrm{N}$, and the relationship between the benefit $\mathrm{X}$ and cost $\mathrm{C}$ for traffic warden to investigate "black car", the game between traffic warden and driver is divided into the following four cases.

Case 1: To severely strike on an illegal operation, $\mathrm{N}>\mathrm{M}$, the benefit of enforcement is higher than the cost of enforcement, $\mathrm{X}>\mathrm{C}$.

First, consider the strategy choice of traffic warden in the game between traffic warden and driver. If driver chooses "legal" strategy, then the profit of traffic warden in choosing "investigate" strategy is -C and the profit of traffic warden in choosing "not investigate" strategy is 0 , because $0>-C$, the choice of "not investigate" strategy is traffic warden's optimal reaction under driver taking "legal" strategy; If driver chooses "illegal" strategy, then the profit of traffic warden in choosing "investigate" strategy is X-C, and the profit of traffic warden in choosing "not investigate" strategy is 0 , because $X-C>0$, the choice of "investigate" strategy is traffic warden's optimal reaction under driver taking "illegal" strategy. Therefore, the traffic warden has no dominant strategy in this game.

Second, consider the strategy choice of driver in the game between traffic warden and driver. By the same way as the above, we can know that the driver has no dominant strategy in this game.

So, the game does not have a pure strategy Nash equilibrium. According to the calculation method of the mixed strategy Nash equilibrium, we make the following calculation.

First, we calculate the probability for traffic warden to take "investigate" strategy under the mixed strategy Nash equilibrium strategy. Assume the probability for traffic warden to take "investigate" strategy is $p$, the probability for traffic warden to take "not investigate" strategy is 1-p, then the expected income of driver in choosing "legal" strategy is $\mathrm{p}^{*}(\mathrm{Y}$ $\mathrm{M})+(1-\mathrm{p})^{*}(\mathrm{Y}-\mathrm{M})$, the expected income of driver in choosing "illegal" strategy is $\mathrm{p}^{*}(\mathrm{Y}-\mathrm{N})+(1-\mathrm{p}) * \mathrm{Y}$.

Make the two equal, $\mathrm{p}^{*}(\mathrm{Y}-\mathrm{M})+(1-\mathrm{p})^{*}(\mathrm{Y}-\mathrm{M})=\mathrm{p} *(\mathrm{Y}-\mathrm{N})+$ $(1-p)^{*} \mathrm{Y}$, we can calculate out $\mathrm{p}=\mathrm{M} / \mathrm{N}$.

Second, we calculate the probability for driver to take "illegal" strategy under the mixed strategy Nash equilibrium strategy. Assume the probability for driver to take "illegal" strategy is q, the probability for driver to take "legal" strategy is $1-\mathrm{q}$, then the expected income of traffic warden in choosing "investigate" strategy is $(1-q) *(-C)+q^{*}(X-C)$, the expected income of traffic warden in choosing "not investigate" strategy is $(1-q) * 0+q * 0$.

Make the two equal, $(1-\mathrm{q}) *(-\mathrm{C})+\mathrm{q} *(X-\mathrm{C})=(1-\mathrm{q}) * 0+\mathrm{q} * 0$, we can calculate out $\mathrm{q}=\mathrm{C} / \mathrm{X}$.

According to the two formulas, we can deduce the following conclusions:

(1) The probability for traffic warden to take "investigate" strategy is positively correlated with the cost for drive to legally operate taxi business, that is to say, the greater the cost for drive to legally operate taxi business, the higher the probability for traffic warden to take "investigate" strategy, which is in accordance with the internal cooperation motivation for law enforcement agency to maintain the interests of the taxi management agencies.

(2) The probability for traffic warden to take "investigate" strategy is negatively correlated with the cost for drive to illegally operate taxi business, that is to say, the greater the cost for drive to illegally operate taxi business, the lower the probability for traffic warden to take "investigate" strategy, which is consistent with the economic rationality of law enforcement agency.

(3) The probability for driver to take "illegal" strategy is positively correlated with the cost for traffic warden to investigate "black car", that is to say, the greater the cost for traffic warden to investigate "black car", the higher the probability for driver to take "illegal" strategy, which is consistent with the economic rationality of driver.

(4) The probability for driver to take "illegal" strategy is negatively correlated with the benefit for traffic warden to investigate "black car", that is to say, the greater the benefit for traffic warden to investigate "black car", the lower the probability for driver to take "illegal" strategy, which is in accordance with the internal motivation for driver to avoid damaging his interest.

Case 2: To severely strike on an illegal operation, $\mathrm{N}>\mathrm{M}$, the benefit of enforcement is lower than the cost of enforcement, $\mathrm{X}<\mathrm{C}$.

In a similar way, we know that the game exist a pure strategy Nash equilibrium ("not investigate”, "illegal").

Due to the lack of effective supply of public transport services, "black car" meet the public travel needs, make up for the lack of public transport services, the social income produced by the "black car" is higher than the social cost produced by the "black car", the cost for the government to dealt with "black car" is higher than the income for the government to dealt with "black car", the government's dominant strategy is tolerate the existence of the "black car". 
Case 3: To gently strike on an illegal operation, $\mathrm{N}<\mathrm{M}$, the benefit of enforcement is higher than the cost of enforcement, $\mathrm{X}>\mathrm{C}$.

In a similar way, we know that the game exist a pure strategy Nash equilibrium ("investigate”," illegal"). Because the cost for driver to illegally operate taxi business is lower than the cost for driver to illegally operate taxi business, drivers have a positive incentive to engage in illegal taxi operation. Because the benefit for traffic warden to investigate "black car" is higher than the cost for traffic warden to investigate "black car", the traffic warden has a positive incentive to investigate "black car". In essence, this is evil of system, is deliberately to utilize the high cost of legal operation and low cost of illegal operation to entice drivers to engage in illegal taxi operation, and to create opportunities for the traffic warden to make punishment on "black car".

Case 4: To gently strike on an illegal operation, $\mathrm{N}<\mathrm{M}$, the benefit of enforcement is lower than the cost of enforcement, $\mathrm{X}<\mathrm{C}$.

In a similar way, we know that the game exist a pure strategy Nash equilibrium ("not investigate", "illegal"). This case is basically the same with the case 2, the difference is that even if the government has to investigate "black car", the driver is steel willing to engage in illegal taxi operation, because the lower penalty issues tolerance signal for "black car", which stimulate the driver to engage in illegal taxi operation.

\section{CONCLUSIONS AND SUGGESTIONS}

On the one hand, technical threshold of the taxi business in China is low, a lot of people can do a taxi driver, on the other hand, taxi business carries out a system of access permission, has a very high monopoly profits. Only have to pay a lot of cost, the driver can become legal taxi driver in the system; otherwise, if engaged in the taxi business, he is illegal, called as "black car". In order to maintain the vested monopoly interests of taxi business, the law enforcement agency takes the "fishing enforcement" to effectively fight against "black car", which caused a lot of trouble, damaged the government image, and destroyed the social harmony. The management of taxi market is in a great trouble. In this paper, we used game theory to analyze the dilemma of taxi management in China, revealed the inherent reasons of "fishing enforcement". According to this analysis, we put forward the corresponding suggestions as follows.

First of all, the service level of public transportation system should be adapted to the needs of city development as soon as possible. To establish a satisfactory bus service is the fundamental solution to the "black car".

Secondly, all the fines should be turned over to the state treasury, and should not be returned to traffic law enforcement agency in any from.

Finally, if the punishment cannot be proved to be correct, not only the all fines should be returned to victim, but also the traffic law agency should be investigated and held accountable.

\section{REFERENCES}

[1] Haowen Feng, Analysis on the causes of fishing enforcement and its decoding strategy based on game theory, Journal of Inner Mongolia Agricultural University (Social Science Edition), 13(2), pp.247-249, 2011.

[2] Yuanzhi Chen, The Analysis of problem of urban transportation from the perspective of game theory: A case study of the improvement and rectification of the gypsy cab drivers, Journal Social Sciences in Nanjing, No.4, pp. 37-42, 2013.

[3] Haowen Feng, Weimin Ouyang, Analysis on the dilemma of college teaching team construction from the perspective of game theory, In: Proceedings of 2016 The International Conference on Humanities and Social Science, Atlantis Press, pp.257-261, 2016

[4] Jiangli Zhang, On administrative trap investigation, Journal of Jinzhong University, No.4, pp47-50, 2014.

[5] Benqian San, The dilemma of law enforcement on "Fishing enforcement" and "Post-Fishing enforcement Era", Peking University Law Journal, No.1, pp.204-219, 2011.

[6] Guangmou Wu, Zhouxiang Lv, Principles and application of game theory, Southeast University Press, Mar. 2009. 